\title{
Identité plurielle ou identité de synthèse : La question du métissage chez Patrick Chamoiseau et Henri Lopes
}

\author{
EI HADJI CAMARA \\ The University of Western Ontario
}

Résumé

Le métissage, culturel ou biologique, semble être la chose la mieux partagée entre les peuples. Il en résulte des identités multiples ou plurielles qui font l'objet de traitements divers par des auteurs comme Patrick Chamoiseau ou Henri Lopes. En effet, l'identité plurielle serait l'appropriation par l'individu ou la collectivité de plusieurs éléments culturels. Il semble cependant qu'il est davantage question d'hybridation et non de juxtaposition d'identités distinctes. À partir d'une lecture ponctuelle de deux romans de ces deux écrivains précités, il s'agira de mettre en relief un tel processus d'appropriation identitaire qui aboutit à la formation d'une identité de synthèse.

Le métissage, culturel ou biologique, semble être la chose la mieux partagée entre les peuples. Il en résulte des identités multiples qui font l'objet de traitements divers par des auteurs comme Patrick Chamoiseau ou Henri Lopes, lesquels ont fait de ce motif un thème central de leurs œuvres. Pour MarieRose Abomo-Maurin, dans Une écriture d'enracinement et d'ouverture (2002), l'identité plurielle serait en effet I'appropriation par l'individu ou la collectivité de plusieurs éléments culturels qui finissent par être les siens. Il semble cependant qu'il est davantage question d'hybridation qui aboutit à une identité de synthèse et non à la juxtaposition de plusieurs identités distinctes. Nous n'évoquons pas ici la problématique de I’hybridation telle qu'envisagée par Homi Bhabha en tant que moyen de résistance, mais comme un état d'être.

En outre, toute appropriation suppose une transformation, et les conditions de cette appropriation appartiennent à chaque individu ou à chaque groupe selon son histoire et son environnement. Une telle démarcation s'observe chez Patrick Chamoiseau qui refuse, dans sa conception de I'«être créole », toute tentative d'assimilation et prône une nouvelle appropriation des valeurs ancestrales. Ne se sentant ni Africain, ni Européen, il clame son état d'être hybride, riche de ses différents apports et de son ouverture au monde. Henri Lopes souscrit à la même thèse, qui met en scène des personnages se lançant à la recherche d'une identité perdue. Aucun d'entre eux ne renie sa tradition, mais tous adoptent la modernité, sans amertume et sans déchirement. Ainsi, le comportement individuel et social, exigé par l'identification, rend possible chez Lopes l'émancipation de l'individu lui-même.

À partir d'une lecture ponctuelle de deux romans de ces écrivains : Texaco (1992) de Patrick Chamoiseau et Le chercheur d'Afriques (1990) d'Henri Lopes, il s'agira de mettre en évidence un tel processus d'appropriation identitaire qui aboutit à la formation d'une identité de synthèse. Notons d'emblée la différence d'approche chez Lopes et Chamoiseau, pour en faire les axes de notre réflexion : assumer la tradition et s'ouvrir à la modernité, telle est la démarche d'Henri Lopes ; alors que pour Patrick Chamoiseau, il faut refuser l'assimilation et accepter sa diversité culturelle.

http://www.brocku.ca/cfra/voixplurielles05-02/index.html 


\title{
Concilier tradition et modernité: la conscience d'une identité plurielle chez Lopes
}

Les bouleversements culturels qu'ont connus les sociétés africaines ont amené les individus à se définir à la fois face à la société traditionnelle et au monde moderne, et à prendre conscience de leur propre individualité. Rappelons cette évidence : aucune société ne reste intacte après le contact des cultures et des civilisations. Conséquence logique, il en résulte des êtres à identités multiples, des identités toujours en mouvement selon Henri Lopes qui, d'une manière générale, se refuse à ressasser I'image négative du contact de l'Afrique avec l'Occident. Il invite à ne pas rejeter en bloc tout ce qui vient de I'ancien colonisateur: il faut prendre à l'Europe ce qu'elle a de bon. Il s'agit en fait d'assumer sa tradition en s'ouvrant à la modernité.

L'héroïne de La nouvelle romance (1976), Wali, s'installant à Bruxelles, comprend vite que l'esprit critique se développe par comparaison : «Vivre à l'étranger, écrit-elle, c'est s'éduquer. 》 (Lopes 192) Le détour par l'autre est nécessaire, et le repli sur l'Afrique suicidaire. C'est ce que dit le narrateur de Sans tam-tam (1977) : «J'en appelle à dessein à des événements et des noms extra africains, car notre histoire et son salut dépassent le continent. Liés à I'humanité, nous sommes solidaires de son passé » (Lopes 40). C'est pourquoi les personnages de Lopes se sentent citoyens du monde. Et Gatsé de dire, dans Sans tam-tam : «tout pays est le mien, tout peuple est mon peuple. » (Lopes 16) ; ce qui est une manière de revendiquer sa citoyenneté mondiale.

Conséquence logique, les textes de Lopes n'affirment guère l'existence d'une aire culturelle aux contours bien définis. L'imagination lopésienne se nourrit partout sur le continent africain. Ses héros revendiquent leur identité nègre, mais l'auteur se garde bien de les cantonner dans une négritude étroite. Ni repli sur la race, ni défense de l'intégrité d'une culture. Au contraire, l'ouverture au reste du monde demeure une priorité. Elle se double d'une ouverture à l'ensemble du monde noir. Ainsi avec Henri Lopes, I'Afrique se décline-t-elle au pluriel. Le continent africain est présenté comme un monde foisonnant de peuples et de langues divers. Lopes en déduit que nous sommes tous des métis culturels. Il rejoint ici la position de I'auteur de Mirages de Paris (1937), Ousmane Socé, qui fait dire à son héros Fara :

\begin{abstract}
Si I'on pousse les choses tout est métis ; il n'y a pas sur la terre une race pure, une civilisation qui ne soit pas métisse. [...] Nous nous trouvons mêlés, tout d'un coup, à la vie universelle. [...] nous nous métissons, tous les jours, dans tous les domaines de l'activité humaine. Et de ce métissage, va naître, en terre africaine, un monde nouveau. (Socé 148-149)
\end{abstract}

C'est pourquoi, pour sa part, Lopes imagine des héros dont aucun ne renie sa négritude, même pas André le métis, ni Raymond I'Antillais qui se réclame de sang africain « avec une fierté de patriote » (Lopes 11) dans Sur l'autre rive paru en 1992. Ces héros, fiers de leur Afrique, adoptent la modernité, sans amertume et sans déchirement, car ils n'ont pas l'impression de renoncer pour autant à eux-mêmes. Il y a 
une sorte d'affirmation identitaire qui se fait par le biais de l'appropriation culturelle et par la mise en avant des traditions ancestrales. En fait pour Lopes, à partir du moment où l'histoire et la tradition africaines ont fait l'objet de négation, il incombe d'abord de les assumer pour enfin pouvoir s'ouvrir au monde.

L'aventure n'a plus d'ambiguïté comme ça a été le cas de Samba Diallo de L'Aventure ambigüe (1961). Les héros d’Henri Lopes sont des nègres pacifiés avec eux-mêmes. Ils ne sont pas tiraillés entre I'Occident et l'Afrique, et n'ont pas à choisir entre l'un et l'autre. Ils ont la possibilité d'être les deux à la fois ; une possibilité offerte par l'appropriation par l'Afrique de la modernité et de son ouverture au monde. On s'en rend bien compte, dans La Nouvelle romance, le rapport entre la culture occidentale et la culture africaine n'est plus conflictuel. Le personnage principal assume son histoire. Quand Wali raconte I'histoire de son Afrique natale aux enfants belges à travers un conte, signe de fidélité à ses origines, elle ne fait qu'évoquer indirectement la différence et l'interférence culturelle. Wali jouit d'un équilibre assimilable à celui d'un métis culturel. Elle a la conscience d'une identité plurielle enrichissante.

En effet, le changement de vision du monde après son voyage en Occident permet à Wali d'aborder la notion de rupture, non pas comme un renoncement à des conceptions antérieures, mais comme I'adoption de nouvelles valeurs. L'homme nouveau assume ainsi comme Wali son avenir d'homme libre en considérant sa propre culture. Une culture que I'auteur essaie de mettre en avant, tout en considérant aussi la culture de l'autre, celle de l'ancien colonisateur. L'œuvre d'Henri Lopes s'inscrit ainsi dans l'exploration de cette identité métisse, et de la condition humaine. Avec Le chercheur d'Afriques, I'inscription de cet esprit moderne se fait sous diverses orientations. D'abord, les tensions entre Africains et Européens sont résorbées par le personnage principal André. Ce « nègre trafiqué par le Blanc » (Lopes 279) est un enfant métis qui vit et évolue entre deux cultures. Mais les oppositions raciales ou culturelles se fondent en une unité.

En effet, dans cette opposition, le personnage d'André se situe au centre des tensions pour dire la vérité, sa nature. Entre sa tante de race noire et son père commandant de race blanche, l'enfant métis dessine son identité. Les excès des uns et des autres sont condamnés dans un esprit d'indépendance. Le chercheur d'Afriques est donc cette manière qui célèbre la réconciliation de l'Afrique avec son histoire, à travers le personnage du métis. Certes, le roman traite de la condition, parfois difficile, du métis, ni blanc, ni noir. Mais au terme de la quête, le personnage sait qui il est : il est avant tout un être humain, riche de ses héritages multiples.

Le métissage d'André est donc à prendre comme une métaphore du métissage culturel de I'Afrique actuelle. André épousera Kani, personnage exemplaire lui aussi, menant jusqu'à la perfection les deux termes de la dualité : être africain et moderne. Elle manie avec aisance la langue française, car cette 
langue est, elle aussi, adoptée sans déchirement. De ce fait, c'est Henri Lopes qui entame une quête dans ses œuvres dont la portée dépasse celle de sa propre identité. En exprimant ainsi, sans complaisance, les oppositions, l'auteur inscrit l'esprit le plus universel dans son œuvre. La différence des races et des nationalités se trouve ainsi neutralisée par l'élément hybride. André devient alors celui qui se présente sous l'indistinction raciale; c'est I'homme universel qui brouille allégrement les lignes de démarcation identitaires. Autrement dit, c'est I'homme universel ou moderne qui sera I'homme de toutes les races.

De la même manière que ses romans mêlent les cultures africaines et européennes, ils brassent les langues. Les personnages vivent entre plusieurs langues et sont des traducteurs, des passeurs d'une langue à l'autre. Il s'agit à la fois de faire tomber les barrières linguistiques en les franchisant allégrement, et de préserver la diversité des langues. Des mots d'autres langues se glissent, sans dissonance aucune, dans le récit français : «Sans transition, nous passions du lingala au français, pour revenir au lingala, voire à un kikongo émaillé de français ou, quelquefois, à un kigangoulou rapiécé de lingala » (Lopes 14). Il s'agit d'une véritable traversée des langues dont le goût est manifeste dans toute l'œuvre de Lopes, particulièrement à partir du Pleurer-rire, dans lequel l'auteur forge une langue africaine imaginaire faite de français et de langues authentiques. Mais c'est surtout dans Le lys et le flamboyant (1997) que l'auteur ira plus loin dans sa quête identitaire en faisant I'éloge de I’hybridité culturelle.

Plurielle, telle est donc l'identité africaine d'aujourd'hui. Henri Lopes réfute une équation simpliste à deux termes, comme il rejette tout manichéisme. L'Africain n'est pas déchiré entre deux cultures: la sienne et celle de l'ancien colonisateur. C'est la culture universelle qui s'offre à lui. De ce fait, Lopes en vient à effacer les différences. Il récuse, en fin de compte, la prétendue opposition entre la culture européenne et les autres.

L'identité africaine qui naît de la diversité du monde est transculturelle. Cette identité refuse toute clôture et ne se laisse pas enfermer dans une culture particulière. C'est la raison pour laquelle, dans les romans d'Henri Lopes, il y a une grande circulation d'hommes, de langues, de cultures, à l'image de la diversité du monde. Ses personnages rejettent les structures communautaires jugées archaïques, et s'affirment comme des individus libres. S'ils retournent aux sources de leurs identités premières, c'est pour les assumer, non pas pour s'y fixer. Pas d'amnésie sur leur passé, pas de rejet non plus de ce qu'ils sont devenus ; à savoir des êtres mobiles, pluriels, et différents. Il s'agit de refuser toutes les clôtures, de ne pas se laisser enfermer dans l'une de leurs identités mais de les embrasser toutes. Les différentes langues qui se côtoient, les multiples références culturelles, africaines et non africaines, la mobilité des personnages principaux, etc., font bien du multiculturalisme une revendication de l'imaginaire lopésien.

Cependant, la question est traitée différemment par Patrick Chamoiseau qui en donne une dimension beaucoup plus politique. Là où Lopes conçoit le métissage à l'échelle de l'individu, Chamoiseau 
le pense en rapport avec la destiné de tout un peuple : le peuple antillais, en l'occurrence à travers une esthétique dite de la créolité.

\section{Refuser I'assimilation et accepter la diversité culturelle chez Chamoiseau}

Dire que les Antilles françaises et la Métropole sont liées par une histoire ancienne est une lapalissade. Mais il importe de relever dans ce long parcours une date, celle du 14 mars 1946 qui correspond à I'adoption du texte érigeant la Réunion, la Martinique, la Guyane et la Guadeloupe en départements français. En effet, cette départementalisation qu'a défendue Aimé Césaire avec ardeur a suscité beaucoup d'espoir, en ce sens qu'elle pouvait mettre fin aux inégalités sociales et faciliter l'intégration des classes défavorisées, malgré quelques avis discordants.

La société antillaise, profondément marquée par des siècles de traite et d'esclavage, souffrait dans sa chair, selon les mots de Césaire. Car les structures familiales traditionnelles sont désintégrées, et les individus atomisés. C'est pourquoi la départementalisation apparaissait comme le cadre unique capable de réunir les différentes composantes de cette société sous le contrôle de la France. Elle pallierait ce manque identitaire qui fait que, comme dans le cas des chaînes jetées à la mer par honte, tout ce qui déshonore est passé sous silence. Devenir français, semble-t-il, leur rendrait donc la parole, mais aussi leur dignité d'homme, tout en favorisant une certaine cohésion sociale: « cette identité d'assimilation nous sauvegardait du chaos identitaire levé des plantations » (Chamoiseau 217), dira le narrateur d'Écrire en Pays dominé (1997). Or, c'est cette perception à la limite naïve de la société antillaise par rapport à la nouvelle politique que dénonce Chamoiseau. Il s'en prend à tous ceux qui ont présenté l'attachement à la France comme l'avenir des Antilles, car c'est eux qui, par leur action, ont perpétué le néo-colonialisme, et rendu impossible la résistance et la valorisation de soi face à la domination coloniale.

Pour cet auteur, la politique assimilationniste reste une forme de colonisation plus cruelle qui conduit à I'anéantissement de l'Être antillais par un procédé d'aliénation culturelle. Elle a contribué à vider les Antillais de leur substance : «la départementalisation nous sépara de nous-mêmes » (Chamoiseau 227). L'Antillais devient stérile devant ses propres valeurs en contribuant lui-même à la promotion et à la vulgarisation de la culture occidentale, ce qui est une autodestruction. Car les valeurs de culture héritées du monde de la plantation sont volontairement ou involontairement ignorées. C'est pourquoi la départementalisation est vue comme une domination silencieuse de la métropole sur les Antilles, tout comme les politiques de décentralisation menées dans les années 1980. À ce sujet, Chamoiseau a raison de s'interroger sur la manière dont on peut résister et exprimer sa différence lorsqu'on dépend de l'autre.

Il inscrit donc son combat dans le retour aux valeurs de soi, et dans la lutte contre l'idéologie dominante dans l'esprit du dominé. Ce dernier n'est plus traumatisé comme chez Memmi, mais 
complètement amnésique, voire anéanti sur le plan culturel et social, parce qu'ayant perdu toute mémoire collective. Chamoiseau constate, pour la déplorer, cette perte de la mémoire ancestrale, conséquence de l'abandon des traditions rurales qui sauvegardaient la transmission d'une langue et d'une culture. C'est pourquoi dans Texaco, en relatant l'évolution d'un quartier pauvre de Fort-de-France baptisé « Texaco » (symbole de la cohabitation entre tradition et modernité) à travers l'histoire de Marie-Sophie Laborieux, il revient sur toutes les luttes menées par le peuple martiniquais, voire antillais, pour y trouver des repères. L'évocation comme «lieu de mémoire », selon l'expression de Pierre Nora, de la plantation, de la Cale du bateau ou de I'habitation traditionnelle dans laquelle se transmettaient des fragments d'histoires à travers les récits des conteurs, participe de cette entreprise. Puisque ce sont ces lieux qui inaugurent pour la plupart des Antillais le début d'une vie nouvelle.

On voit bien pourquoi l'auteur fait de cette mémoire collective perdue une dimension importante de sa quête identitaire à travers la transmission par la parole. Car, comme I'affirme Lorna Milne dans Patrick Chamoiseau : Espaces d'une écriture antillaise (2006) : «Qu'elle soit collective ou individuelle, toute quête d'identité implique la recherche d'une origine » (Milne 37). C'est ainsi que la narratrice de Texaco, Marie-Sophie, s'est toujours montrée fière et garante de la mémoire paternelle qu'elle veut perpétuer afin de rester attachée à ses origines.

En réponse au «Marqueur de parole » qui s'exprime par écrit et en français, trahissant ainsi I'héritage paternel, Marie-Sophie dit ne pas vouloir trahir cette mémoire par l'écriture. Pour elle, l'écrit appauvrit les histoires et crée un décalage entre celles-ci et I'Histoire qui serait officielle, puisqu'il ne peut rendre compte que de manière partielle et partiale en légitimant un seul point de vue. C'est une des raisons pour lesquelles, dans ses « cahiers », dont des extraits sont plusieurs fois cités dans Texaco, elle a «poursuivi la parole de son père » (Chamoiseau 423) en essayant d'être le plus fidèle possible ; cette parole du père s'étant elle-même nourrie des récits d'Idoménée, épouse d'Esternome et mère de MarieSophie. Il n'est donc pas étonnant de constater que l'auteur, qui est aussi le double du «Marqueur de parole », selon Lydie Moudileno, s'inscrit dans la lignée des conteurs traditionnels pour concilier les exigences de l'écrit et les subtilités de la parole. Cela se traduit dans les textes de Chamoiseau par la présentation de nombreux points de vue à travers les notes, les lettres, etc., pour combler les lacunes de l'écrit.

Ce projet esthétique porté par l'auteur est au service d'une cause, pourrait-on dire. En inaugurant avec Chronique des sept misères (1986) ce que Maignan-Claverie appelle, dans Le métissage dans la littérature des Antilles françaises (2005), le «métissage des écritures » (Maignan-Claverie 24), Chamoiseau compte rendre dans ses moindres détails l'âme antillaise. D'ailleurs, pour les trois chantres de la créolité (Bernabé, Chamoiseau et Confiant), le recours à l'écriture n'est qu'un moyen qui permet «la 
projection plus ou moins esthétique d'un Moi » (Lettres créoles 50). Il s'agit surtout, tout en recourant à la langue de l'Autre, de refuser toute forme d'assimilation, condition sine qua none de l'existence d'une culture créole, voire antillaise. Tel est le défi que compte relever l'auteur, à savoir la réalisation d'une identité de synthèse, en refusant tout compromis.

De ce fait, ce qui doit amener l'être antillais à s'accepter dans ce qu'il a de spécifique, c'est la mise en avant de ses propres références pour que sa culture survive, sans tomber dans le piège de l'ethnocentrisme, en s'ouvrant à I'Autre. En fait, et c'est ce qui motive son combat, semble-t-il, l'auteur entrevoit les mêmes conséquences désastreuses de la colonisation dans cette nouvelle forme de domination qui résulte de la départementalisation qu'il qualifie de « domination silencieuse » (Chamoiseau 21) dans Écrire en pays dominé. Car cette forme de domination qui « neutralise les expressions les plus intimes des peuples dominés » (Chamoiseau 21) est tout aussi aliénante.

À partir de ce moment, reconnaissant la diversité de sa société, Chamoiseau met en avant le principe de pluralité qui naît de la rencontre des cultures. L'identité créole doit donc être envisagée comme une identité ouverte, et non exclusive. La revendication d'une telle identité est un moyen de résorber les contradictions culturelles, ethniques, voire politiques des Antilles françaises. Dès lors, et c'est ce qui fait l'originalité de l'auteur et de tout le mouvement de la Créolité, la démarche identitaire ne s'inscrit plus dans I'affirmation de son existence contre I'Autre, mais dans une perspective relationnelle avec lui. En ouvrant ainsi l'identité créole à tous, Chamoiseau manifeste son intention de sortir du schéma binaire noir/blanc dont le dépassement s'avère nécessaire.

L'examen de la question du métissage chez Lopes et Chamoiseau nous a donc permis de mettre en relief la prise de conscience d'une identité plurielle chez ces deux auteurs. Lopes nous a montré qu'il est possible de concilier tradition et modernité sans brutalité, alors que Chamoiseau nous a donné la preuve qu'on peut assumer plusieurs identités si celles-ci ont été ou sont les nôtres.

Plusieurs romanciers avant eux, entre autres Cheik Hamidou Kane et Ousmane Socé, ont tenté d'analyser la subjectivité de cette condition, en espérant que s'instaurent enfin entre l'Afrique et les autres continents, entre le centre et la périphérie, des relations de respect mutuel et de solidarité, ainsi que des échanges culturels fructueux. Autrement dit, transformer le « conflit des cultures » en une rencontre de cultures qui peut donner naissance à une société nouvelle. Mais la problématique identitaire telle que posée par Lopes ou par Chamoiseau est une démarche nouvelle, peut-être guidée par la donne récente, en I'occurrence la globalisation culturelle. C'est pourquoi la relation à l'autre est fondamentale dans l'œuvre de Lopes. Il est un romancier en quête d'une écriture apte à dire son rapport au monde : un monde nouveau, un monde fragmenté. Le roman devient dés lors ce lieu, cet espace sans frontières qui 
peut accueillir tous les langages, dire la singularité d'un homme et la pluralité des mondes auxquels il appartient

L'ère des destinés individuelles étant terminée, l'Africain doit s'insérer dans son nouvel environnement. Du coup, la prise en compte de cette situation nouvelle devient une revendication récurrente du roman africain au sud du Sahara. Ce dernier parlera désormais le langage de l'universel, le langage du dévoilement de la condition humaine. Pour parler ce langage, toutes les formes d'expression littéraire sont permises. C'est peut-être aussi une des raisons pour lesquelles les écrivains de la Créolité, à travers leur manifeste intitulé L'Eloge de la Créolité (1989), ont fini par se démarquer de leurs prédécesseurs et par créer leur propre «langue d'écriture » qu'ils situent aux confluents du français et du créole, de l'écrit et de l'oral. Ceci pour rendre compte de la pluralité des références culturelles et sociales des Antilles.

De ce fait, l'identité culturelle, dans le cadre d'une identité multiculturelle, n'est pas seulement sauvée, mais elle est aussi l'élément qui sauve l'écrivain d'une perte certaine de repères. La création littéraire contribue ainsi à l'instauration et à la diffusion du sentiment collectif de l'identité culturelle métisse de la société africaine contemporaine, mais aussi de la société antillaise. 


\section{Références}

Abomo Maurin, Marie-Rose. Henri Lopes : une écriture d'enracinement et d'universalité. Sous la Direction d'André-Patient Bokiba et Antoine Yila. Paris : L'Harmattan, 2002.

André, Sylvie, et Jean Bessière. Multiculturalisme et identité en littérature et en art. Paris : L'Harmattan, 2002.

Bernabé, Jean, Patrick Chamoiseau, et Raphaël Confiant. Eloge de la créolité. Paris : Gallimard, 1989.

Biringanine, Ndagano. Nègre tricolore. Littérature et domination en pays créole. Paris : Maisonneuve \& Larose, 2000.

Blachère, Jean-Claude. Négritures : les écrivains d'Afrique noire et la langue française. Paris : L'Harmattan, 1993

Césaire, Aimé. Discours sur le colonialisme. Paris : Présence africaine, 1995.

Chamoiseau, Patrick. Ecrire en Pays dominé. Paris : Gallimard, 1997.

Texaco. Paris : Gallimard, 1992.

et Raphaël Confiant. Lettres créoles. Paris : Hatier, 1991.

Chronique des sept misères. Paris : Gallimard, 1986.

Dabla, Sewanou. Nouvelles écritures africaines, Romanciers de la seconde génération. Paris : L'Harmattan, 1986.

Gauvin, Lise. L'écrivain francophone à la croisée des langues. Paris: Karthala, 1997.

Kane, Cheik Hamidou. L'Aventure ambiguë. Paris : René Julliard, 1961.

Kourouma, Ahmadou. Les Soleils des indépendances. Paris : Seuil, 1970.

Lopes, Henri. Le lys et le flamboyant. Paris : Seuil, 1997.

. Le chercheur d'Afriques, Paris : Seuil, 1990.

Le Pleurer- rire. Paris : Présence Africaine, 1982.

Sans tam-tam.Yaoundé: Clé, 1977.

La Nouvelle romance. Yaoundé : Clé, 1976.

Maignan-Claverie, Chantal. Le métissage dans la littérature des Antilles française. Le complexe d'Ariel. Paris : Karthala, 2005.

Mbanga, Anatole. Les Procédés de création dans l'œuvre de Sony Labou-Tansi. Paris : L'Harmattan, 1996.

Memmi, Albert. Portrait du colonisé. Paris : Gallimard, 1985.

Milne, Lorna. Patrick Chamoiseau. Espaces d'une écriture antillaise. New York : Editions Rodopi B.V, 2006.

Moudileno, Lydie. Parades postcoloniales. La fabrication des identités dans le roman congolais. Paris : Karthala, 2006.

Mouralis, Bernard. Individu et collectivité dans le roman négro- Africain d'expression française. Abidjan : Annales de I'Université d'Abidjan, 1969. Tome 2.

http://www.brocku.ca/cfra/voixplurielles05-02/index.html 
Nora, Pierre. «Entre mémoire et histoire. » Les lieux de mémoire. Sous la direction de Pierre Nora. Tome 1. Paris : Gallimard, 1997. 23-43.

Perret, Delphine. La Créolité. Espace de création. Martinique : Ibis Rouge, 2001.

Relouzat, Raymond. Tradition orale et imaginaire créole. Martinique : Ibis Rouge, 1998.

Rosello, Mireille. Littérature et identité créole aux Antilles. Paris : Karthala, 1992.

Socé, Ousmane, Mirages de Paris, Paris : N.E.L, 1937.

Sony, Labou- Tansi, La vie et demie, Paris : Seuil, 1979. 